\title{
TINGKAT KEPUASAN PASIEN RAWAT JALAN \\ TERHADAP KETEPATAN WAKTU PELAYANAN OLEH TENAGA KESEHATAN DI PUSKESMAS RANOTANA WERU KECAMATAN WANEA KOTA MANADO
}

\author{
${ }^{1}$ Syamrinah Panggato \\ ${ }^{2}$ B. S. Lampus \\ ${ }^{2}$ Wulan P.J. Kaunang
}

\author{
${ }^{1}$ Kandidat SKRIPSI Fakultas Kedokteran Universitas Sam Ratulangi Manado \\ ${ }^{2}$ Bagain Ilmu Kedokteran Masyarakat Fakultas Kedokteran Universitas Sam Ratulangi \\ Manado \\ Email:paai_manado@yahoo.com
}

\begin{abstract}
Community Health Centre (PHC), is one means by which essential public health services in Indonesia, both individuals and society. Government to develop health centers in order to bring health services to the people who most still live in rural areas. General purpose of the study was to determine the level of patient satisfaction to the timeliness of outpatient services by health district health center Ranotana Weru Wanea Manado City. The research objective was to determine specifically the level of outpatient satisfaction in terms of opening hours room service cards, after hours room service card, the card room admission procedure, the waiting time to sea a doctor, the doctor's room service check, pharmacies and service officers when they came to health personnel in Health Center Ranota Weru. The research was conducted at the health center districts Wanea Ranotana Weru. The method used is descriptive survey using a questionnaire as an instrument of data collection. Target population in this study were all outpatients (adults) in November 2011 that meet the criteria to be respondents. Conclusion: Based on these results, it can be concluded that the timeliness of service to the health center Ranotana Weru most satisfied.
\end{abstract}

Keywords: patient satisfaction, timeliness, health service.

\begin{abstract}
Abstrak : Pusat Kesehatan Masyarakat (Puskesmas) merupakan salah satu sarana pelayanan kesehatan masyarakat yang penting di Indonesia, baik perorangan maupun masyarakat. Pemerintah mengembangkan Puskesmas dengan tujuan untuk mendekatkan pelayanan kesehatan kepada masyarakat yang sebagian besar masih tinggal di pedesaan. Tujuan penelitian secara umum adalah mengetahui tingkat kepuasan pasien rawat jalan terhadap ketepatan waktu pelayanan oleh tenaga kesehatan Puskesmas Ranotana Weru Kecamatan Wanea Kota Manado. Tujuan penelitian secara khusus adalah mengetahui tingkat kepuasan pasien rawat jalan dalam hal jam buka pelayanan kamar kartu,jam tutup pelayanan kamar kartu, prosedur penerimaan kamar kartu,waktu tunggu sampai diperiksa dokter, pelayanan dokter di kamar periksa, pelayanan petugas apotik dan waktu datang tenaga kesehatan di Puskesmas Ranota Weru. Penelitian ini dilaksanakan di Puskesmas Ranotana Weru kecamatan Wanea. Metode penelitian yang digunakan bersifat survey deskriptif dengan menggunakan kuisioner sebagai instrument pengumpulan data. Populasi target dalam penelitian ini adalah seluruh pasien rawat jalan (dewasa) pada bulan November 2011 yang memenuhi kriteria menjadi responden. Simpulan: Berdasarkan hasil penelitian ini, maka dapat disimpulkan bahwa pelayanan terhadap ketepatan waktu di Puskesmas Ranotana Weru sebagian besar merasa puas.
\end{abstract}

Kata kunci: kepuasan pasien, ketepatan waktu, pelayanan kesehatan. 
Pusat kesehatan masyarakat (Puskesmas) merupakan salah satu sarana pelayanan kesehatan masyarakat yang penting di Indonesia, baik perorangan maupun masyarakat. Pemerintah mengembangkan Puskesmas dengan tujuan untuk mendekatkan pelayanan kesehatan kepada masyarakat yang sebagian besar masih tinggal di pedesaan. Program kesehatan yang diselenggarakan oleh Puskesmas merupakan program pokok yang wajib dilaksanakan oleh pemerintah untuk melindungi penduduknya, termasuk mengembangkan program khusus untuk penduduk miskin (Azwar, 1996). Puskesmas Ranotana Weru merupakan salah satu pelaksana pelayanan kesehatan di wilayah kerjanya dengan komposisi jumlah tenaga kesehatan adalah 44 orang. Angka kunjungan pasien ke Puskesmas selama tahun 2010 sebanyak 15.632 Pasien dengan jumlah kunjungan lama 15.392 pasien dan kunjungan baru 240 pasien. Jadwal pelayanan kesehatan di Puskesmas Ranotana Weru menurut survey awal di mulai dari hari Senin sampai Sabtu dengan jam pelayanan dimulai pukul 08.00 -15.00. Berdasarkan hal-hal tersebut maka penulis merasa perlu untuk melakukan penelitian mengenai tingkat kepuasan pasien rawat jalan terhadap ketepatan waktu pelayanan oleh tenaga kesehatan Puskesmas Ranotana Weru Kota Manado.

\section{TUJUAN DAN MANFAAT}

Untuk mengetahui tingkat kepuasan pasien rawat jalan terhadap ketepatan waktu pelayanan oleh tenaga kesehatan Puskesmas Ranotana Weru Kecamatan Wanea Kota Manado. Manfaat penelitian diharapkan dapat menjadi informasi, masukan, dan pertimbangan bagi instasi yang bersangkutan agar lebih memperhatikan kualitas pelayanan kesehatan kepada pasien. Untuk menambah pengetahuan masyarakat agar dapat menjadi referensi atau pembanding tentang pelayan dan sebagai bentuk penerapan atau aplikasi dari ilmu pengetahuan yang telah diperoleh pada bangku perkuliahan.

\section{METODE}

Penelitian ini bersifat deskriptif. Tempat penelitian dilaksanakan di Puskesmas Ranotana Weru Kota Manado yang telah dilaksanakan selama bulan NovemberJanuari 2012. Populasi target dalam penelitian ini adalah seluruh pasien rawat jalan (dewasa) pada bulan November 2011 di Puskesmas Ranotana Weru Kota Manado dan sampelnya yaitu seluruh pasien rawat jalan di Puskesmas Ranotana Weru. Data yang dikumpulkan berasal dari kuisioner dan dokumen yang tersedia di Puskesmas Ranotana Weru berupa profil, laporan tahunan dan diolah untuk selanjutnya dibuat presentase dan data tersebut disajikan dalam bentuk table distribusi frekuensi.

\section{HASIL}

Tabel 1. Distribusi responden berdasarkan tingkat kepuasan terhadap jam buka pelayanan pada kamar kartu.

\begin{tabular}{lll}
\hline $\begin{array}{l}\text { Jawaban } \\
\text { Responden }\end{array}$ & Jumlah & \% \\
\hline Sangat Puas & 14 & 28 \\
Puas & 27 & 54 \\
Cukup Puas & 6 & 12 \\
Tidak Puas & 3 & 6 \\
Sangat Tidak Puas & - & - \\
\hline Total & 50 & 100 \\
\hline
\end{tabular}

Tabel 2. Distribusi responden berdasarkan tingkat kepuasan terhadap jam tutup pelayanan pada kamar kartu.

\begin{tabular}{lcc}
\hline Jawaban & Jumlah & \% \\
Responden & & 22 \\
\hline Sangat Puas & 11 & 60 \\
Puas & 30 & 18 \\
Cukup Puas & 9 & - \\
Tidak Puas & - & - \\
Sangat & - & \\
Tidak Puas & & 100 \\
\hline Total & 50 & \\
\hline
\end{tabular}


Tabel 3. Distribusi responden berdasarkan tingkat kepuasan terhadap prosedur penerimaan pada kamar kartu.

\begin{tabular}{lcc}
\hline Jawaban & Jumlah & $\mathbf{\%}$ \\
Responden & & - \\
\hline Sangat Puas & - & 64 \\
Puas & 32 & 22 \\
Cukup Puas & 11 & 14 \\
Tidak Puas & 7 & - \\
Sangat & - & \\
Tidak Puas & & 100 \\
\hline Total & 50 & \\
\hline
\end{tabular}

Tabel 4. Distribusi responden berdasarkan tingkat kepuasan mengenai waktu tunggu sampai diperiksa dokter.

\begin{tabular}{lcc}
\hline Jawaban & Jumlah & \% \\
Responden & & - \\
\hline Sangat Puas & - & 50 \\
Puas & 25 & 36 \\
Cukup Puas & 18 & 10 \\
Tidak Puas & 5 & 4 \\
Sangat Tidak Puas & 2 & 100 \\
\hline Total & 50 & \\
\hline
\end{tabular}

Tabel 5. Distribusi responden berdasarkan tingkat kepuasan terhadap pelayanan dokter di kamar periksa.

\begin{tabular}{lcc}
\hline Jawaban & Jumlah & \% \\
Responden & & 2 \\
\hline Sangat Puas & 1 & 76 \\
Puas & 38 & 16 \\
Cukup Puas & 8 & 6 \\
Tidak Puas & 3 & - \\
Sangat Tidak Puas & - & 100 \\
\hline Total & 50 & \\
\hline
\end{tabular}

Tabel 6. Distribusi responden berdasarkan tingkat kepuasan terhadap pelayanan petugas di bagian apotik.

\begin{tabular}{lcc}
\hline Jawaban & Jumlah & \% \\
Responden & & \\
\hline Sangat Puas & - & - \\
Puas & 41 & 82 \\
Cukup Puas & 9 & 18 \\
Tidak Puas & - & - \\
Sangat Tidak Puas & - & - \\
\hline Total & 50 & 100 \\
\hline
\end{tabular}

Tabel 7. Distribusi responden berdasarkan tingkat kepuasan terhadap waktu datang tenaga kesehatan di Puskesmas.

\begin{tabular}{lcc}
\hline Jawaban & Jumlah & \% \\
Responden & & \\
\hline Sangat Puas & - & - \\
Puas & 34 & 68 \\
Cukup Puas & 12 & 24 \\
Tidak Puas & 4 & 8 \\
Sangat Tidak Puas & - & - \\
\hline Total & 50 & 100 \\
\hline
\end{tabular}

\section{BAHASAN}

Tingkat kepuasan pasien terhadap pelayanan tenaga kesehatan di pengaruhi oleh faktor-faktor seperti daya tanggap, jaminan, empati, tepat waktu, kenyamanan, ketersediaan, dan bukti langsung. Pada penelitian ini yang akan diteliti hanya mengenai ketepatan waktu sedangkan faktor-faktor lain yang mempengaruhi tidak akan diteliti pada penelitian ini, akan tetapi faktorfaktor tersebut ikut mempengaruhi tingkat kepuasan pasien rawat jalan terhadap ketepatan waktu pelayanan oleh tenaga kesehatan Puskesmas Ranotana Weru. Pada penelitian yang dilakukan selama bulan November 2011 diperoleh sampel berdasarkan kriteria inklusi sebanyak 50 responden. Kepuasan pasien yang terjadi karena menerima pelayanan kesehatan dari puskesmas menghasilkan beberapa manfaat salah satu diantaranya adalah mendorong terciptanya loyalitas pasien. ${ }^{3}$ Berdasarkan penelitian tingkat kepuasan pasien dalam hal ketepatan waktu maka pelayanan di Puskesmas Ranotana Weru sudah memenuhi tingkat kepuasan pasien rawat jalan karena hampir sebagian besar pasien merasa puas dengan ketepatan waktu pelayanan yang diberikan namun masih ada juga faktor-faktor lain yang dapat mempengaruhi kepuasan pasien terhadap pelayanan oleh tenaga kesehatan. Untuk me-ningkatkan pemanfaatan fasilitas layanan kesehatan milik pemerintah, tingkat kepuasan pasien harus diukur dan dianalisis. Hasil analisis tersebut kemudian akan menunjukkan mutu layanan yang diselenggarakan telah memenuhi harapan pasien atau belum. Jika belum memenuhi 
harapan pasien, harus segera dilakukan upaya peningkatan mutu layanan kesehatan. Oleh sebab itu, pengukuran tingkat kepuasan pasien perlu dilakukan secara berkala, teratur, akurat, dan berkesinambungan. ${ }^{2}$

\section{SIMPULAN}

Berdasarkan hasil penelitian pada pasien rawat jalan di Puskesmas Ranotana Weru Kota Manado pada bulan November 2011 adalah:

1. Sebagian besar pasien merasa puas terhadap jam buka pelayanan pada kamar kartu di Puskesmas Ranotana Weru.

2. Sebagian besar pasien merasa puas terhadap jam tutup pelayanan pada kamar kartu di Puskesmas Ranotana Weru.

3. Sebagian besar pasien merasa puas terhadap waktu tunggu sampai diperiksa dokter di Puskesmas Ranotana Weru.

4. Sebagian besar pasien merasa puas terhadap prosedur penerimaan pada kamar kartu di Puskesmas Ranotana Weru.
5. Sebagian besar pasien merasa puas terhadap pelayanan dokter pada kamar periksa di Puskesmas Ranotana Weru.

6. Sebagian besar pasien merasa puas terhadap pelayanan bagian apotik di Puskesmas Ranotana Weru.

7. Sebagian besar pasien merasa puas terhadap ketepatan waktu datang tenaga kesehatan di Puskesmas Ranotana Weru.

\section{KEPUSTAKAAN}

1. Azwar A. Pengantar Administrasi Kesehatan. Jakarta: Bina Rupa Aksara, 1996; hal.38-76.

2. Pohan IS. Jaminan Mutu Layanan Kesehatan: Dasar-dasar Pengertian Dan Penerapan. Jakarta: EGC, 2007; Hal.1361.

3. Tjiptono, Fandy. Total Quality Service. Yogyakarta: ANDI, 1997. 